\title{
Exploring the mental health and psychosocial problems of Congolese refugees living in refugee settings in Rwanda and Uganda: a rapid qualitative study
}

Anna Chiumento ${ }^{1 *}$ D , Theoneste Rutayisire ${ }^{2}$, Emmanuel Sarabwe ${ }^{3}$, M. Tasdik Hasan ${ }^{1}$, Rosco Kasujja ${ }^{4}$, Rachel Nabirinde ${ }^{4}$, Joseph Mugarura ${ }^{4}$, Daniel M. Kagabo ${ }^{5}$, Paul Bangirana ${ }^{6}$, Stefan Jansen ${ }^{7}$, Peter Ventevogel ${ }^{8}$, Jude Robinson ${ }^{9}$ and Ross G. White ${ }^{1}$

\begin{abstract}
Background: Refugees fleeing conflict often experience poor mental health due to experiences in their country of origin, during displacement, and in new host environments. Conditions in refugee camps and settlements, and the wider socio-political and economic context of refugees' lives, create structural conditions that compound the effects of previous adversity. Mental health and psychosocial support services must address the daily stressors and adversities refugees face by being grounded in the lived reality of refugee's lives and addressing issues relevant to them.

Methods: We undertook a rapid qualitative study between March and May 2019 to understand the local prioritisation of problems facing Congolese refugees living in two refugee settings in Uganda and Rwanda. Thirty free list interviews were conducted in each setting, followed by 11 key informant interviews in Uganda and 12 in Rwanda.

Results: Results from all interviews were thematically analysed following a deductive process by the in-country research teams. Free list interview findings highlight priority problems of basic needs such as food, shelter, and healthcare access; alongside contextual social problems including discrimination/inequity and a lack of gender equality. Priority problems relating to mental and psychosocial health explored in key informant interviews include discrimination and inequity; alcohol and substance abuse; and violence and gender-based violence.

(Continued on next page)
\end{abstract}

\footnotetext{
* Correspondence: Anna.Chiumento@liverpool.ac.uk

'Department of Primary Care and Mental Health, University of Liverpool, Liverpool, England

Full list of author information is available at the end of the article
}

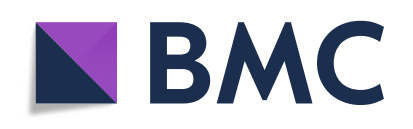

(- The Author(s). 2020 Open Access This article is licensed under a Creative Commons Attribution 4.0 International License, which permits use, sharing, adaptation, distribution and reproduction in any medium or format, as long as you give appropriate credit to the original author(s) and the source, provide a link to the Creative Commons licence, and indicate if changes were made. The images or other third party material in this article are included in the article's Creative Commons licence, unless indicated otherwise in a credit line to the material. If material is not included in the article's Creative Commons licence and your intended use is not permitted by statutory regulation or exceeds the permitted use, you will need to obtain permission directly from the copyright holder. To view a copy of this licence, visit http://creativecommons.org/licenses/by/4.0/. The Creative Commons Public Domain Dedication waiver (http://creativecommons.org/publicdomain/zero/1.0/) applies to the data made available in this article, unless otherwise stated in a credit line to the data. 


\begin{abstract}
(Continued from previous page)
Conclusions: Our findings strongly resonate with models of mental health and psychosocial wellbeing that emphasise their socially determined and contextually embedded nature. Specifically, findings foreground the structural conditions of refugees' lives such as the physical organisation of camp spaces or refugee policies that are stigmatising through restricting the right to work or pursue education. This structural environment can lead to disruptions in social relationships at the familial and community levels, giving rise to discrimination/inequity and gender-based violence. Therefore, our findings foreground that one consequence of living in situations of pervasive adversity caused by experiences of discrimination, inequity, and violence is poor mental health and psychosocial wellbeing. This understanding reinforces the relevance of feasible and acceptable intervention approaches that aim to strengthening familial and community-level social relationships, building upon existing community resources to promote positive mental health and psychosocial wellbeing among Congolese refugees in these settings.
\end{abstract}

Keywords: Mental health and psychosocial support, Qualitative, Refugees, Community-based support, Humanitarian settings, Post-conflict, DIME

\section{Introduction}

Globally more than 70 million people are displaced, with over $80 \%$ in countries neighbouring their country of origin [1], many in low- and middle-income countries (LMICs) with limited resources. These include protracted situations where refugees have been living in insecure settings for generations [2]. Mental health is impacted by a complex interplay of social determinants [3], which play out in unique ways in the social ecology of refugee settings. This includes structural conditions of adversity such as insecure asylum status, restricted opportunities to work or pursue education, and limited access to services, all of which can compound pre-displacement exposure to conflict or traumatic events and exacerbate psychological distress and mental health problems [4-6]. Displaced populations also face adversity due to loss of or separation from family, the erosion of social support mechanisms and community networks, and potential cultural or linguistic barriers to negotiating health services [7]. Refugee settings compound this adversity by establishing social, economic and political systems that may challenge the long established social and cultural norms that governed and shaped everyday life in their communities before they became refugees [8]. For example, in some settings refugees face restrictions on the right to work, to cultivate land, or pursue higher education. Such conditions diminish the agency of refugees and may create dependency on outside institutions. They alsoplace demands on social and cultural norms over generations, which can impact on the way refugees relate to one another, and can increase the risks of violence and discrimination $[8,9]$.

Conceptual frameworks aid our understanding of the complex and cyclical relationships between the ecology of refugee settings - including familial, social, community, and structural context such as conditions of poverty and disadvantage - and mental health and psychosocial wellbeing. These include frameworks that foreground conditions of adversity that arise through daily stressors such as difficulties accessing basic necessities of food and shelter $[10,11]$ and the impact of losing personal, familial, and social resources essential for mental wellbeing [12]. The ecological model [13] emphasise the micro-, meso- and macro-level settings in which humans are embedded, directly and indirectly influencing individuals through continuous individual, family, community, and social environment interactions. This model encourages attention to the multiple levels at which health and wellbeing are impacted, for example, a problem such as gender-based violence that manifests in the family may be an expression of gender relations at the community level. These frameworks and model emphasise creating supportive and enabling environments that allow displaced refugees to rebuild a sense of self and regain a sense of control to promote positive mental health. Acknowledging these connections, mental health and psychosocial support (MHPSS) services increasingly recognise the significance of social and cultural factors shaping experiences of mental health problems and appropriate responses; and the importance of integrating MHPSS services into multi-layered health, social and community systems [7]. Community-based MHPSS services are recommended to build on individual and collective capacities and resources [14-18], overcoming refugees' hesitancy to engage with formal services [19].

Consequently, to be acceptable and successful, approaches to MHPSS services must be rooted in the daily stressors and adversities refugees face, situating mental health and psychosocial problems in their socio-cultural context. To achieve this, research to understand local community needs and priorities is critical $[18,20]$. Gaining this understanding can help identify opportunities to empower existing social supports, and to inform the contextual adaptation of MHPSS programs to ensure their acceptability and relevance [19]. Recognising this, we applied the Design, Implementation, Monitoring and Evaluation (DIME) rapid qualitative approach [21] with 
Congolese refugees living in a refugee camp in Rwanda and a refugee settlement in Uganda. This study forms part of the COSTAR project [22] which will contextually adapt, implement, and evaluate a community-based group psychosocial intervention with Congolese refugees living in these settings.

\section{Methods}

We applied the DIME rapid qualitative approach developed and applied extensively with adults in low resource settings [20, 21], including with refugee populations [23-25]. The rapid qualitative assessment involves two stages: first conducting free-list interviews with local community members to identify problems the community face and a brief description of each. The results are analysed to identify priority problems relating to mental health and psychosocial wellbeing. Second, the priority problems are further explored in key informant interviews with community representatives knowledgeable about the selected topics. We conducted the study in each site (30 free list and 10-15 key informant interviews). Interviews were conducted in Kinyarwanda in Rwanda, and Congolese Kiswahili in Uganda.

\section{Setting}

Over the last two decades, the Democratic Republic of the Congo (DRC) has experienced three large-scale conflicts: the First Congo War (1996-7) and Second Congo War (1998-2003), and the Kivu Conflicts in Eastern DRC which continue to date [26, 27]. As of December 2019, Uganda and Rwanda host 397,638 and 76,266 DRC refugees respectively [28]. The two COSTAR study refugee settings are located $480 \mathrm{~km}$ apart: the Kyangwali refugee settlement in Uganda, and Gihembe refugee camp in Rwanda. Both settings are administered by the respective country government, with operational support from the United Nations High Commissioner for Refugees (UNHCR).

Gihembe refugee camp was established in 1997, and as of March 2015 hosts 14,774 refugees [29] in 3030 densely populated households. The camp was established to host survivors of the Mudende massacre [30]. Mudende was a refugee camp in Western Rwanda hosting Congolese refugees from Eastern DRC which in August and December 1997 suffered attacks by armed groups crossing the border from the DRC. There are an approximately equal number of male and female refugees with families averaging 4-5 people [29], and given their protracted stay, all speak Kinyarwanda. The majority of Gihembe refugees are Christian, with a minority Muslim population. The Kyangwali refugee settlement was established in the 1960s and currently hosts 109,207 people, of which 108,164 are refugees and 1403 are asylum seekers [31]. The majority of the refugees in
Kyangwali are from the DRC $(105,514)$, followed by South Sudan (3273), Rwanda (327), Burundi (71), Kenya (10), and Somalia (10, 32). The Kyangwali settlement has approximately 39,846 households spread over a large geographical area, each with access to land to cultivate. The settlement has an approximately equal number of males and females [32] with families averaging 5-6 people, and the common language is Kiswahili. Both Gihembe and Kyangwali refugee settings host international and national refugee organisations, and have elected refugee representatives who represent community perspectives on administrative and governance matters.

Congolese refugees have experienced evolving Ugandan and Rwandan refugee policy and practice, with both countries recently committing to the United Nations Comprehensive Refugee Response Framework [28, 33]. Uganda follows a self-reliance refugee model which includes the right to work, freedom of movement, and access to education and healthcare [34, 35]. For example, $53.5 \%$ of refugees in Kyangwali report that they have an occupation [36]. Rwanda currently adopts a graduated refugee camp model with the aim of fostering greater refugee integration, and with support delivered through a cash and voucher mVisa system that allows families to make their own food choices [30]. The refugees in Gihembe currently do also have the right to establish businesses inside and outside the camp, and to move outside the camp to cultivate rented farmland or pursue employment.

Given the long and complex history of conflict in the DRC and the Great Lakes Region more broadly, refugees in these settings have been displaced at different times [28]. Gihembe refugee camp hosts a more established population who have been living there since 1997 [28], with some recent arrivals as a result of renewed hostilities in the DRC in 2012-13. Conversely, Kyangwali refugee settlement has experienced a pattern of continuous arrivals since its establishment, with a recent surge in arrivals as a result of the 2018-19 DRC Conflicts [28]. As a result, Kyangwali and Gihembe host a mix of more and less established Congolese refugees who may have experienced different levels of access to resources and support services since arrival. This is important as differences in resource access and support services can become a source of adversity through intra-community conflict over perceived inequity in resource allocation.

\section{Participants}

We interviewed male and female adult Congolese refugees living in Gihembe Camp, Rwanda; and Kyangwali Settlement, Uganda. Free list interviews were conducted with a convenience sample of 30 participants in each site $(n=60)$ purposively selected according to the inclusion 
Table 1 Demographics of free list and key informant interview respondents

Variable Uganda Rwanda Total

Free list interview respondents
Gender
Female
Male
Age
$<=25$
$25-45$
$46-65$
$>66$

Marital status

Single

Married

Widowed

Education

Informal / none

Primary

Secondary

Tertiary

Length of time in refugee setting

$<=1$ year
$2-5$ years
$6-10$ years
$11-20$ years
$>21$ years
Lifetime (under 2 when arrived in
camp)
Missing

Key informant interview respondents

Gender

Female

Male

Age

$<=25$

$25-45$

46-65

$>66$

Marital status

Single

Married

Widowed

Education

Primary

Secondary

Tertiary
Table 1 Demographics of free list and key informant interview respondents (Continued)

\begin{tabular}{llll}
\hline Variable & Uganda & Rwanda & Total \\
\hline \multicolumn{1}{l}{ Informal / none } & 1 & 5 & 6 \\
Length of time in refugee setting & & & \\
$\quad<=1$ year & 1 & 0 & 1 \\
2-5 years & 5 & 1 & 6 \\
6-10 years & 3 & 0 & 3 \\
11-20 years & 1 & 3 & 4 \\
> 21 years & 1 & 12 & 13 \\
$\quad \begin{array}{l}\text { Lifetime (under 2 when arrived in } \\
\text { camp) }\end{array}$ & 0 & 0 & 0 \\
\hline
\end{tabular}

criteria: Congolese refugee living in Gihembe/Kyangwali, over 18 years of age, fluent in Kinyarwanda or Congolese Kiswahili, and able and willing to talk to the research team. Participants were recruited from a selection of villages/neighbourhoods (umudugudu in Kinyarwanda) spread geographically across each site, with efforts made to achieve gender and age-range representation.

Key informant participants were purposively identified by free list interviewees as knowledgeable about the priority topics to be explored. Key informants were local community members including community and religious leaders, teachers, etc. The key informants did not have professional roles to respond to the mental health and psychosocial problems explored in interviews (i.e. they were not community counsellors, or health care or social workers). This approach aims to ensure that interview responses prioritise local community perceptions of problems and solutions, rather than views underpinned by professional training [21]. The demographic profile of free list and key informant interviewees are summarised in Table 1:

\section{Data collection}

Research was conducted between March and April 2019. Twelve interviewers in Kyangwali (8 males, 4 females), and 8 in Gihembe ( 4 males, 4 females) who spoke the participants language were locally recruited. All interviewers received a 3-day training in the basic principles of qualitative interviewing, including how to conduct free list (FL) interviews, and the key principles of ethics including obtaining voluntary informed consent.

FL interviewers worked in pairs, one asking questions and probing responses, and the second making a verbatim written record of what was said in the local language. Each FL interview lasted between 20 and $45 \mathrm{~min}$. In FL interviews participants were asked to list all the problems that adults living in Gihembe/Kyangwali face, and to provide a 1-3 line description of each. At the end of each interview the transcript was reviewed to ensure 
Table 2 Problems reported by free list respondents

\begin{tabular}{ll}
\hline Problem & $\begin{array}{l}\text { Number of respondents who } \\
\text { mentioned the problem } \\
(N=30)^{\mathrm{a}}\end{array}$
\end{tabular}

\section{UGANDA}

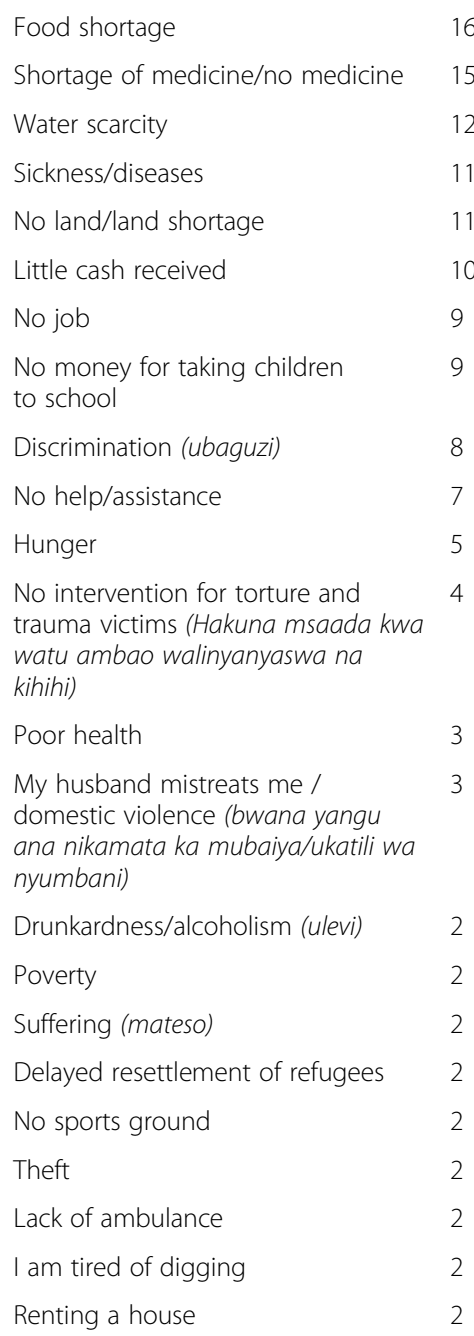

\section{RWANDA}

Education
Unemployment
Not having access to adequate
health services
Poverty status
Briquettes (firewood) are not enough
and are polluting
The money we get is not enough
Housing
Food that is not enough
The problem of unwanted
pregnancies among girls (Ikibazo
cy'inda z'indaro mu bakobwa)
Aid is not enough
The problem of official papers

Table 2 Problems reported by free list respondents (Continued)

\begin{tabular}{|c|c|}
\hline Problem & $\begin{array}{l}\text { Number of respondents who } \\
\text { mentioned the problem } \\
(N=30)^{\mathrm{a}}\end{array}$ \\
\hline Misconduct among youth & 5 \\
\hline $\begin{array}{l}\text { The problem of inequity/inequality } \\
\text { (between refugees and Rwandan } \\
\text { nationals) (ubusumbane) }\end{array}$ & 4 \\
\hline Malnutrition & 4 \\
\hline Illiteracy & 3 \\
\hline $\begin{array}{l}\text { Gender-based violence (ihohoterwa } \\
\text { rishingive kugitsina) }\end{array}$ & 3 \\
\hline $\begin{array}{l}\text { Drug abuse (kwishora mu } \\
\text { biyobyabwenge) }\end{array}$ & 3 \\
\hline Trauma (Guhungabana) & 2 \\
\hline $\begin{array}{l}\text { The problem of drunkenness } \\
\text { (Ubusinzi) }\end{array}$ & 2 \\
\hline $\begin{array}{l}\text { The problem due to the fact that } \\
\text { some are taken abroad and others } \\
\text { are left behind (i.e. some refugees } \\
\text { are resettled abroad whilst others } \\
\text { remain in the camp). }\end{array}$ & 2 \\
\hline Parents who misbehave & 2 \\
\hline $\begin{array}{l}\text { Men who don't take family } \\
\text { responsibilities }\end{array}$ & 2 \\
\hline $\begin{array}{l}\text { The problem related to } \\
\text { entertainment }\end{array}$ & 2 \\
\hline $\begin{array}{l}\text { People don't have freedom (Ukuntu } \\
\text { abantu batajya bagira ikintu } \\
\text { cy'ubwisanzure) }\end{array}$ & 2 \\
\hline We don't have electricity & 2 \\
\hline $\begin{array}{l}\text { The problem related to neighbors } \\
\text { who don't get along sometimes } \\
\text { (Ikibazo cyo kutabana neza } \\
\text { n'abaturanyi rimwe na rimwe) }\end{array}$ & 2 \\
\hline
\end{tabular}

${ }^{a}$ Responses mentioned by only one person have been removed

clarity of the written record, and the interviewers reviewed the list of problems to identify those that might be related to mental health and psychosocial wellbeing (defined as those relating to thinking, feeling or relationships [21]). Interviewers then asked participants to recommend community members knowledgeable about each problem to be invited to key informant interviews.

Following FL interview data analysis to select priority problems (described below), key informant (KI) interviews were conducted to gather more detailed data on the priority problems relating to mental health and psychosocial wellbeing. Interviewers were provided an additional 1 (Gihembe) or 1.5-day (Kyangwali) training for KI interviews, covering asking open-ended questions and probing skills, and refreshing key principles of research ethics and voluntary informed consent. In KI interviews the participants were asked to provide: a) a description of the problem, including symptoms and effects; b) perceived causes of the problem; c) effects of the problem on the individual 
Table 3 Problem of discrimination/ubaguzi (Uganda)

\section{Description of the problem}

Some tribes don't get into community leadership

Fights among different tribes

Linguistic discrimination among different tribes

Back-stabbing among different tribes

Labeling people who don't speak Swahili as Rwandan

Different religious sects don't visit people who belong to other sects

Parents educate the boy child over the girl child

Responding and talking in a cruel way to people of a different tribe

Different tribes harass and threaten each other

People live in fear of other tribes

Destroying gardens of people from other tribes

Perceived causes of the problem

People speaking different languages

Scheming within different tribes to fail or twart members of tribes other than one's own (fitina katika makabila)

Lack of love for one another

Immigration and having different nationalities

Parents think the boy child is more important than the girl child

Having numerous religious sects

Problems related to tribalism (shida za ukabila)

Resettlement status some have and others do not

Land wrangles

Lack of trust within families

Harsh living conditions

People have different customs

Difference in years lived in the settlement

Illiteracy

Effects on those with the problem and those close to them

Fighting

Killing one another

May lead to tribal disputes

Hatred within villages (machuki)

There is no peace and freedom (hakuna amani na uhuru)

Imprisonment

Lack of co-operation (between community members) hinders development

Early pregnancies associated with difficulties at delivery and reduce chances to lead a good life

Poisoning (kulogana)

Leads to poverty status

Harassment (kunyanyaswa)

What do people currently do to address the problem

Sensitizing community about effects of discrimination

Advice giving

Teaching people to live in harmony and love one another

Reporting problems to NGOs

Separating tribes that are fighting
Number of respondents $(n=$

6

4

4

3

2

2

1

1

Number of respondents

5

4

2

2

1

1

1

Number of respondents

6

4

3

3

2

2

2

1

Number of respondents 
Table 3 Problem of discrimination/ubaguzi (Uganda) (Continued)

\begin{tabular}{ll}
\hline Imprisonment of perpetrators of discrimination & 1 \\
Reporting to the village chairperson & 1 \\
Having community dialogues about discrimination & 1 \\
Government putting announcements on the radios about its effects & 1 \\
What should be done about the problem if resources were available & Number of respondents \\
Advising people to love one another & 4 \\
Establishing strict laws to fight discrimination & 3 \\
Sensitizing the communities about effects of discrimination & 2 \\
Games uniting people & 2 \\
All people should be taken abroad & 1 \\
Formation of community development groups & 1 \\
Joint business venture & 1 \\
Establishing more places where water can be got & 1 \\
Give them money to buy the food they need. & 1 \\
Government should pass rules against discrimination & 1 \\
Government should punish perpetrators & 1
\end{tabular}

and those close to them; d) what people currently do about the problem; and e) what people think could be done about the problem. Interviewers again worked in pairs with one asking questions and the other recording a written summary responses in the local language. Creating a written record is the recommended DIME approach, which seeks to facilitate rapid data collection and analysis in humanitarian settings. Written transcripts were reviewed with the $\mathrm{KI}$ at the end of each interview to ensure clarity of meaning and completeness. Each KI interview lasted on average $60 \mathrm{~min}$, including obtaining consent. Should the participant have more to say or be knowledgeable about additional problems identified for KI interviews, interviewers would agree a subsequent date and time to continue the interview.

\section{Ethics}

Ethical approval for the study was provided by the University of Liverpool, the University of Makerere, Uganda National Council for Science and Technology, and the University of Rwanda. Additional administrative approvals were obtained to conduct research in the Kyangwali refugee settlement and the Gihembe refugee camp.

All participants were approached by interviewers, provided a brief description of the study, and asked if they would consider taking part. If in agreement the interviewers would find a quiet location to discuss the participant information sheet, answer any questions, and complete a written informed consent form with the participant, including consent to reporting anonymised research results. For illiterate participants a line or mark was accepted in lieu of a signature, alongside witness confirmation (a participants' nominated family member or friend) of the voluntary nature of consent. Participants were free to pause or end the interview at any time without repercussions, and were provided refreshments during the interviews. Study trainers were available throughout data collection and analysis, and conducted daily team de-briefs. All data was anonymised through participant identification numbers. The only exception to this was the names of potential KIs recommended by FL participants which were recorded separately to FL data and destroyed once interviews had been conducted.

\section{Data analysis}

All data was analysed in the original languages at each site by the interviewers, supported by the trainers who were provided verbal translations where required. A thematic analysis approach was applied that was deductively driven by the interview questions, as recommended in the DIME manuals. For FL analysis interviewing pairs reviewed written FL interview transcripts and listed problems and their reporting frequency on a summary sheet. When problems were worded differently a consensus decision was made as to whether the items were the same or different to one another. When the same, the most appropriate wording was selected for the summary sheet by consensus. If no consensus could be reached, both items were listed as separate problems. Once complete, the problem lists were re-ordered by frequency alongside a single brief description using the participants wording that interviewers agreed best described the problem. Summary sheets were then reviewed with local community stakeholders 
Table 4 Problem of inequity/inequality /ubusumbane (Rwanda)

\section{Description of the problem}

We have limited job opportunities because of having refugees status (papers)

Those who have a chance to find a job outside the camp, you realize that their salaries are not equal to those of nationals

When you finish secondary school you don't have financial support to go to the University like Rwandans

Poverty status

We cannot get bank loans because we don't have guarantee to give and also the fact that we are not Rwandans

In the sector of shelter within the camp, there is inequality (ubusumbane); they do not permit us to construct new house as we wish nor do repairs

There is gender inequity and gender inequality (ubusumbane bujyanye $n^{\prime}$ igitsina).

As refugees are not respected (Gusuzugurwa kw' impunzi)

Refugees who are teachers in schools outside the camp do not earn the same salaries as Rwandans. That causes teachers from the camp feel they are not like others, they feel less value and are ashamed (ipfunwe) like during the meeting.

You realize that some people have jobs while others don't

You can tell from how different people are dressed

Here in the camp there are cases of people who mostly pay school fees for boys only while girls are left behind

Those in old age and those with disabilities are not supported by the government while nationals are supported by the government.

When you are (living) alone other families walk on top of you (i.e. look down on you: lyo uri nyakamwe indi miryango ikugenda hejuru)

Rwandans have Mutuelle de Santé (Community-Based Health Insurance Scheme) but we don't have it

There is inequality with regard to children born from unwanted pregnancies outside marriage or union of sorts; they are not cared for like other children born in accepted ways (married couples)

\section{Perceived causes of the problem}

What causes it, before anything else, it is because we are refugees

Some of the reasons given for refugees getting paid less is because there are things refugees get for free, like water, food, and shelter - they do not pay rent

Refugees don't have enough rights with regard to employment

You find that some are been educated, while others are not

\section{Effects on those with the problem and those close to them}

Jealousy (amashyari) among people

Sadness / feeling upset (ufite akababaro) when you go out to look for a job and it is not offered to you because you are a refugee

To do a job when you are not happy and you do it feeling less valued and ashamed (biguteye ipfunwe)

Gives way to self-isolate and disown self (Kwigunga no kwiyanga bikaza)

To lose hope and potentially cause you psychological problems (kwitakariza ikizere byanagutera uburwayi bwo mu mutwe)

Experience PTSD-like symptoms (Guhura $n^{\prime}$ ihungabana)

Poverty status

Feeling despair (Kwiheba)

Internal conflicts (umwiryane)

Substance abuse (Kujya mu biyobyabwenge)

Not respected (gusuzugurwa) because you are a refugee

Inability to provide for family
Number of respondents 
Table 4 Problem of inequity/inequality /ubusumbane (Rwanda) (Continued)

Disputes/discord (Amakimbirane)

Increased unemployment rates among refugee communities

Delinquency among youths

Girls turn to survival sex

\section{What do people currently do to address the problem}

At the camp level there is a program of resettling people to third countries

There are NGOs working in the camp that support those who are unemployed through giving them financial support in the form of business capital

There are NGOs working in the camp that support the youth, provide them with scholarship

For those working outside the camp, salaries have been increased

[An NGO] supports refugees and put them in therapy groups, for those people who experienced problems

NGOs through campaigns tries to sensitize people that boy and girl are equal

The government (of Rwanda) has permitted refugees to learn traffic laws and pass their driving test

What should be done about the problem if resources were available

Be paid the same salaries as Rwandans

Teachings meant to sensitize refugees about inequity (Inyigisho zo gukangurira impunzi kubijyanye $n^{\prime}$ ubusumbane)

To give us same rights as Rwandans

The government of Rwanda can have mercy on us and give us access to health and education

Have the opportunity to get loans from the banks

Youths who completed secondary school be given a financial opportunities to go to university

Those in old age be given financial support on different occasions

Increase vocation training opportunities among the youth to prevent them from turning to substance use

Introduce a literacy school for adults so that they can learn how to read

To set up a library with enough books so that educated people continue to acquire various knowledge

Increasing the money we are given every month

Those of us who are yet to be resettled to a third country, they can also help us to go abroad because in the camp we feel like people living in isolation

1

Number of respondents

1

1

1

1

1

Number of respondents 3

2

2

1

1 (representatives of organisations in the refugee settings) to identify problems potentially related to mental health and psychosocial problems - defined as those relating to thinking, feelings and relationships - to explore in KI interviews. Additional considerations in the selection of priority problems included that they were mentioned by multiple respondents and contained descriptions that appeared to be severe in terms of impact.

A similar process was followed for KI interviews analysis with the interviewers and trainers reviewing written transcripts and recording responses to: a) description; b) perceived causes; c) perceived effects on the individual and those close to them; d) what people currently do; and e) what people think could be done. These responses were compiled into summary tables alongside the codes of participants. Where participants had reported what interviewers agreed was referring to the same thing the interviewers would agree the wording of the item and record both participant codes alongside it.

For the purpose of reporting the data has been translated into English, with original language terms - in Kiswahili for Uganda, or Kinyarwanda in Rwanda - retained where relevant. Analysis was conducted independently at each site, before the results were compared across the two sites. This approach sought to ensure analytical attention to the specificities of the data at each site, before considering the data sets alongside one another to identify potential commonalities and differences in the experiences of Congolese refugees in two settings, following previous DIME studies that have adopted this approach [37]. 
Table 5 The problem of domestic violence/ukatili wa nyumbani (Uganda)

Description of the problem
Husbands beating their wives at home (wabwana
wamepiga wabibi wao ndani yamanyumba)
Children are not permitted to go to school (watoto
wamekatazwa kwenda shuleni)
Beating children (kupiga watoto)
Marital rape/forced love (upendo wanguvu)
Misunderstandings in the family
Child labour
Wives attacking their husbands in bars
Child marriages
Not finding happiness (kukosa furaha)
Poverty status
Wounds on the body from beatings
Husband and wife doing business together,
husband takes all the money (bibi na bwana
kufanya biashara, bwana anachukuwa yote)
Separation (kuwachana kw wake na wanawume)
Parents physically fighting in the presence of
children (wazazi kugombana mebere ya watoto
wawo)
Children's performance deteriorates at school
Men use family resources to marry other women/
polygamy
Women deny husbands sex when they are drunk
Sale of home property
Women reporting husbands to in-laws
Quarreling (ugomvi)
Use of abusive language (kukuwa na maneno
mabaya kwa masemo)
Women losing body weight
Perceived causes

\section{Perceived causes of the problem}

Poverty

Drunkardness / alcoholism (ulevi)

Food and money aid received

Polygamy

Deception/lies (kudanganya)

Discrimination among children (ubaguzi kati ya watoto) (e.g. parents treating one child favourably)

Hunger

Rape

Early marriages

Weak laws on domestic violence

Coming from a family that practices domestic violence

Indiscipline (kukosa hadabu)

Sex denial

\section{Number of \\ respondents}

4

3

3

2

2

2

2

1

1

1

1

1

1

1

1

1

1

1

Number of respondents

6

6

3

2

2

1

1

1

1

1
Table 5 The problem of domestic violence/ukatili wa nyumbani (Uganda) (Continued)

\begin{tabular}{ll}
\hline Not believing in God & 1 \\
Infidelity & 1 \\
Quarrels in the home & 1 \\
Not providing basic needs to family members & 1 \\
Women refusing to work expecting free things & 1 \\
Cultural beliefs (men beat women to show & 1 \\
masculinity) (wanawume wanapiga wake ili & \\
waonyeshe ubwana bwawo) & 1 \\
Many bars everywhere & 1 \\
Fighting in the homes & 1
\end{tabular}

Effects on those with the problem and those close to them

Number of respondents

Death

HIV/AIDS 4

Separation of couples 4

Poverty 2

Sustaining injuries from fights 2

Inability to pay school fees for children 2

Misunderstandings between couples 2

No peace in the home (hakuna usalama nyumbani) 2

Child neglect 2

Street children 2

Imprisonment 2

Lack of happiness in the home (kukosa furaha kwa 1 nyumba yake)

Mistreatment of children 1

Child labour 1

Quarrels (ugonvi) 1

Hatred from neighbours for having sleepless nights 1

Living a promiscuous life 1

Scars on the body 1

Early marriages 1

Children lack parental love $\quad 1$

Disability 1

\section{What do people currently do to address the Number of} problem

There are people in the villages who counsel 8 people (pako batu muma village ba kushhulia watu) Reporting to the police 5

Sensitizing communities on domestic violence 4

Praying for the perpetrators in church 3

Report to NGOs 2

Clubs in schools teach children child protection 1

Circulating information and educational materials 1 about domestic violence

World vision supplements on food being given to 1 
Table 5 The problem of domestic violence/ukatili wa nyumbani (Uganda) (Continued)

reduce hunger

\begin{tabular}{ll}
$\begin{array}{l}\text { What should be done about the problem if } \\
\text { resources were available }\end{array}$ & $\begin{array}{l}\text { Number of } \\
\text { respondents }\end{array}$ \\
$\begin{array}{l}\text { Government to make strict laws against domestic } \\
\text { violence }\end{array}$ & 4 \\
Getting employment & 3 \\
$\begin{array}{l}\text { Stop bribery (rushwa) at police posts (from } \\
\text { offenders) }\end{array}$ & 3 \\
Family counseling (mashauri ya nyumbani) & 2 \\
Startup capital for business & 2 \\
Making associations that support affected families & 2 \\
Imprisoning offenders & 2 \\
Get more development projects & 1 \\
$\begin{array}{l}\text { Teaching children in schools to report domestic } \\
\text { violence }\end{array}$ & 1 \\
Giving awards to domestic free homes & 1 \\
Closing bars, as they are too many & 1 \\
\hline
\end{tabular}

\section{Results}

The Uganda and Rwanda FL results are provided alongside one another. We then identify the priority mental health and psychosocial problems selected for KI interviews, and present KI interview results for thematically similar problems explored across both sites.

\section{Free-list interviews}

In Table 2 we list the problems reported by the $60 \mathrm{FL}$ respondents in Uganda $(n=30)$ and Rwanda $(n=30)$ in decreasing order of frequency.

Across both settings the most commonly reported problems relate to daily living such as poverty, unemployment, and lack of healthcare access and education opportunities. Alongside these participants reported social problems including alcohol and drug abuse, sexual and gender-based violence, teenage pregnancy, and discrimination/segregation. Problems related to their refugee status were also highlighted, including difficulties obtaining official papers or in Rwanda obtaining employment if one's status is identified as "refugee", and a lack of resettlement opportunities. This problem was mentioned more often by refugees in Rwanda as compared to Uganda, which may reflect that the majority of study respondents had been living in Gihembe for over 21 years.

Problems potentially related to mental health and psychosocial wellbeing (i.e. relating to thinking, feeling and relationships) selected for KI interviews in Uganda include discrimination (ubaguzi) $(n=8)$, no intervention for torture and trauma victims (hakuna musada kwa watu ambao walinyanyaswa na kihihi) $(n=4)$, domestic violence (ukatili wa nyumbani) $(n=3)$, and alcohol and substance abuse (kutumia pombe na madawa ya ulevi mubaya) reported as "drunkardness/alcoholism" (ulevi) $(n=2)$. After discussion between the Ugandan research team and local stakeholders the problem of alcohol abuse was expanded to incorporate substance abuse because these were felt to be interconnected problems that should be considered holistically. In Rwanda KI interviews explored unwanted pregnancies amongst girls ( $n=$ $7)$, inequity/inequality (ubusumbane) $(n=4)$, sexual and gender-based violence (ihohoterwa rishingiye kugitsina) $(n=3)$, and drug abuse (kwishora mu biyobyabwenge) $(n=3)$. We chose further explore the problem of discrimination (Uganda) and inequity/inequality (Rwanda) because as a problem related to social relationships and cohesion this was felt demand require further unpacking to consider its relationship to mental wellbeing.

\section{Key informant interviews}

We summarise KI interview responses for mental health and psychosocial problems across the two sites that explore similar themes of social inequalities, sexual and gender-based violence (SGBV), and alcohol and drug abuse. The results are drawn from $11 \mathrm{KI}$ interviews in Uganda, with 7 respondents exploring all three problems, and 4 addressing one or two; and $16 \mathrm{KI}$ interviews in Rwanda, with 4 respondents exploring each problem.

First we present the results for the problems of discrimination (ubaguzi, Uganda, Table 3) and inequity/inequality (ubusumbane, Rwanda, Table 4):

These results contain similarities, including identifying gender as a key site of discrimination, particularly noting the impact of discrimination and inequity/inequality on the education of girls. Another similarity is the connection between experiencing discrimination or inequity/inequality and emotional impacts such as "jealousy", "lack of love for one another", "sadness/feeling upset" and experiencing "shame". Recommendations for responding to these problems from both settings highlight the role of dialogue and learning.

The results also identify key differences in the problem description, with participants in Uganda making frequent reference to discrimination by tribe, religious sect, and language. In contrast, in Rwanda inequity/inequality is identified as arising from participants' refugee status in contrast to Rwandan nationals (although this is also identified in the results from Uganda, it is less frequently mentioned). These differences potentially reflect the refugee communities in each setting, with Uganda hosting a greater diversity of nationalities, languages, and ethnic origin.

Second, we present results for the problem of domestic violence (ukatili wa nyumbani, Uganda, Table 5), and sexual and gender-based violence (ihohoterwa rishingiye kugitsina, Rwanda, Table 6). 
Table 6 The problem of sexual and gender-based violence/ihohoterwa rishingiye kugitsina (Rwanda)

\section{Description of the problem}

Widows, single mothers not living with their husband/partners, we are raped

There are men who sexually exploit and abuse minor girls: there have been incidences of men who rape young girls (Hari nk' abagabo bahohotera abana: kubafata ku ngufu)

In reality violence here is there. Personally, I faced violence with regard to resettlement, when my husband died, I married another and then he left me and went away.

When time came for resettlement, UNHCR brought me back because I don't have a

husband, because I lacked (a man) to sign for me, I was to go in 2015

They give her sweets and then sleep with her yet she is 7 years old

Many young girls whose mothers are frequently drunk, they are many who have been violated when they have 4 years

There is time they find me in the house, I am with my children and they want to beat (kunkubita) me

You may go to the hospital seriously ill; they fail to immediately care for you (bakakurangarana), an you may even die there

Men want their separate M-Visa and it is not given to them

Violence is present here and includes not having a market in the camp

They do not give us enough inkwi (traditional firewood)

\section{Perceived causes of the problem}

Poverty

Lack of employment

Alcohol abuse (Ubusinzi)

It is because we are crammed in one place (Ni uko twirundiye hamwe)

Children are lured by fritters and sweets

Raising children when we are not capable

Hunger

Thirsty

\section{Effects on those with the problem and those close to them}

Adolescent girls give birth at a young age

It causes many illnesses when someone sexually assaults you and he is HIV positive, you may get infected (bigutera) with illness

We used to cook for our children but these [briquettes] have starved us

They wander around with kids

Raising children when we are not capable

To start a family when they are still young

Have a C-section when they are giving birth

Selling drugs

$\mathrm{He} / \mathrm{she}$ does not have anywhere to go, runs away from parents because they [parents] are financially disadvantaged, he/she end up suffering and has nowhere to stay

\section{What do people currently do to address the problem}

They come and talk to us in quartiers, and when there are some sick [people] they comfort (bakabakomeza) them.

To report it to responsible institutions

Penalize (guhana) those who tried to cover it up

We talk to them and advise (tukabagira inama) them

We shun the behaviour through "Akagorobak'Ababyeyi"- 'Parents' evening' [NGO program]

That child is hastily taken to hospital, they do test for her and follow her up

What should be done about the problem if resources were available

Even though it is not widely accepted, boys and girls would go to learn vocations
Number of respondents

3

2

2

1

1

1

1

Number of respondents

3

2

2

1

1

1

1

1

Number of respondents

3

2

2

2

1

1

1

1

1

Number of respondents

Number of respondents 
Table 6 The problem of sexual and gender-based violence/ihohoterwa rishingiye kugitsina (Rwanda) (Continued)

\author{
like tailoring and hair dressing and cooking \\ If they could financially support us, we will all find what to do \\ Those in old age would be given jobs \\ To ban those illegal drinks the way they banned Kanyanga (local illegal liquor) \\ We think that they should find another refuge for us \\ They would install for us public lights on the streets and houses \\ When someone is sick and they realize they cannot treat him/her they would \\ immediately refer him/her to main hospital
}

\title{
1
}

1

1

Similarities are notable, including that descriptions of violence are centred on the family - notably the husband and wife relationship - and foreground impacts upon children. Poverty is highlighted as a cause of interpersonal violence, with the role of alcoholism also noted. Both sets of data foreground the health impacts of violence including physical injuries and rape, with a particular emphasis on children as suffering adversely from the effects of violence such as experiencing "child neglect" and "mistreatment". Recommendations for addressing these problems include awareness raising, counselling, enforcing laws against perpetrating violence, and providing education and vocational opportunities.

There are also some notable differences, primarily the role of polygamy as both a cause and consequence of violence in Uganda which was not identified in Rwanda. In Rwanda the role of physical proximity to others in the community is identified a cause of violence which is not present in Uganda, reflecting the role of the physical organisation of the refugee settings in perpetuating violence - with Gihembe densely populated whilst Kyangwali is a large settlement allowing refugees to live in small compounds that are spread out.

Finally, we present the results of the problem of alcohol and substance abuse (kutumia pombe na madawa ya ulevi mubaya, Uganda, Table 7) and drug and alcohol abuse (kwishora mu biyobyabwenge, Rwanda, Table 8).

Results on substance and alcohol abuse across the two settings show significant similarity, including the impact of past experiences causing emotional distress that leads to substance abuse. Another similarity is the impact of alcohol and drug abuse at both the community and family levels, including adding to community insecurity and physical violence within marriages and towards children. Overlap is also evident in recommendations to respond to this problem, with a notable role for giving advice or counselling and enforcing laws, as well as providing employment and vocational opportunities.

\section{Discussion}

This study contributes to understanding the problems faced by Congolese refugees living in two refugee settings in Uganda and Rwanda. Findings identify priority mental health and psychosocial problems that relate to social cohesion and social relationships. Social cohesion is a complex concept that has been conceptualised to contain multiple dimensions, including common values, social order, social solidarity, social networks, and place attachment (see e.g. [38]). We adopt a broad understanding of social cohesion as entailing connectedness, a sense of belonging, and solidarity among refugees [39]. A lack of social cohesion is evident in the problem of discrimination and inequity; and poor social relationships are described in the impact of alcohol and drug abuse and sexual and gender-based violence which affect relationships at the family and community levels. To be acceptable MHPSS services must be rooted in the social ecology of refugees everyday lives [18], and recognise the impact of daily stressors $[10,11]$. To achieve this, study findings will inform the implementation of a community-based group psychosocial intervention that seeks to rebuild intra-community connections, and the adaptation of instruments to evaluate the interventions effectiveness [21].

Problem FL findings reflect dimensions of human development as conceptualised by the United Nations, which builds on Sen's work on human capabilities [40]. Briefly, Sen claims that there is moral value in a person's freedom to achieve wellbeing, which is understood in relation to people's capabilities - their opportunities to do and be what they have reason to value. Notably participants' responses reflect foundational aspects of human development such as access to basic needs including food, shelter, and health care to maintain a decent standard of living; followed by contextual social problems including systemic discrimination, inequality, and gender inequity. This problem prioritisation is important for understanding the daily living conditions of Congolese refugees in Gihembe and Kyangwali, and consequently identifying the impediments to achieving positive mental wellbeing [40]. Prioritising meeting basic needs such as shelter and food is commonly reflected in studies exploring the MHPSS needs of refugees [10]. For example, research with South Sudanese refugees in 
Table 7 The problem of alcohol and substance abuse/kutumia pombe na madawa ya ulevi mubaya (Uganda)

Description of the problem

Abrupt fights at home (mapigano nyumbani)

Drunkards staggering (kuanguka) on the road in broad day light

Drinking alcohol and smoking (kuvuta)

Beating up children

Picking fights with people for no reason (kupigana na watu bila kuwa na shida nao)

Getting lost on the road

Falling on the road

Being dirty everyday

Stealing people's property

Chewing marijuana and selling it (watu wanakula mairungi na kuchuruza)

Raping women (ubakagi wa wanawake)

Spending many hours in bars drinking alcohol

Youth have created groups for smoking marijuana

Increased number of bars which sell alcohol

Being nude in front of children

Hurling insults at people

Stealing food from gardens

Urinating in own trousers

Reeking of alcohol and marijuana

\section{Perceived causes of the problem}

Having no peace at home (kutokuwa na amani ndani ya nymba)

Being in bad company

Wanting to forget many bad thoughts (kutaka kusahau mafikiri mabaya)

Being jobless

When s/he remembers things he went through when in DRC (kama anakumbukavinavyo alipitia ndani ya DRC)

Loosing hope because they have no parents nor job opportunities (kukata tamaa juu hawana wazazi walakazi)

Seeking pleasure (kutafuta raha)

To replicate what youth watch in movies

Received little money which is no good for them and they are not happy because of the hardship in the settlement

Having no say in community matters and no friends (kutokuwa na neno kwa komunote wala kukua bila rafiki)

Lack of self-worth/respect.(ukosefu wa maana wa kibinafsi)

It is a learned habit (born of parents who use alcohol) (ni tabia nazaliwa na bazazi banakunywa pombe)

Alcohol is very cheap

Too many bars open during daytime

Effects on those with the problem and those close to them

When intoxicated they get into fights and are jailed

Poverty within families

Excess use may cause death

Separation/divorce

Diseases in the home

Rape women

Mental disorders (magonjwa ya kichwani)
Number of

respondents

5

3

3

2

2

2

2

1

1

1

1

1

1

1

1

1

1

1

1

Number of respondents

4

4

4

3

3

2

1

1

1

1

1

1

1

Number of respondents 5 
Table 7 The problem of alcohol and substance abuse/kutumia pombe na madawa ya ulevi mubaya (Uganda) (Continued)

\begin{tabular}{|c|c|}
\hline Marital rape (ungono kwa kingufu) & 2 \\
\hline Quarrels with neighbors (kusema mubaya na wajirani) & 1 \\
\hline Motor accidents & 1 \\
\hline Being sacked from jobs & 1 \\
\hline Falling out with friends & 1 \\
\hline People who drink too much lose respect (ukosefu wa heshima) of family members and other people & 1 \\
\hline $\begin{array}{l}\text { After receiving family food ration, the husband wants to sell the food to buy alcohol. This infuriates the wife who then stabs } \\
\text { him with a knife. }\end{array}$ & 1 \\
\hline Domestic violence (ukatiri wa nyumbani) & 1 \\
\hline What do people currently do to address the problem & $\begin{array}{l}\text { Number of } \\
\text { respondents }\end{array}$ \\
\hline Arresting abusers of alcohol and other substances & 7 \\
\hline Community health talks about alcohol and substance abuse. & 5 \\
\hline Religious leaders preaching against alcohol and substance abuse & 2 \\
\hline Laws are in place to prohibit the sale and consumption of alcohol by minors & 2 \\
\hline Advising alcohol abusers to reduce alcohol intake & 2 \\
\hline Engage people in sports so as to spend less time in bars & 1 \\
\hline Relocating bars & 1 \\
\hline Prohibiting children from working in bars and consuming alcohol & 1 \\
\hline What should be done about the problem if resources were available & $\begin{array}{l}\text { Number of } \\
\text { respondents }\end{array}$ \\
\hline Restricting bars to open during daytime & 5 \\
\hline To employ the alcohol abusers & 4 \\
\hline To teach them how to drink responsibly & 4 \\
\hline To enroll alcohol and substance abusers in self-help groups (kufanya vikumbi vya watu wanaokunywa pombe) & 3 \\
\hline To retain children in school & 1 \\
\hline Banning alcohol sale in towns & 1 \\
\hline Gazette bars in residential places & 1 \\
\hline Police to patrol bars during daytime & 1 \\
\hline Organizing sport activities for children and youth & 1 \\
\hline Conduct abrupt searches in bars to arrest people who employ minors & 1 \\
\hline Proper disposable of alcohol sachets so that children don't lick them & 1 \\
\hline
\end{tabular}

Uganda report similar problems securing basic needs, and poor social cohesion including ethnic tensions, gender-based violence, and child protection concerns [41]; findings echoed in studies with refugees and refugee service providers in Tanzania, Rwanda and Burundi [42]. This problem prioritisation is complemented by theoretical exploration of the changed social context and systems in refugee settings that can create conditions that facilitate gender inequity and SGBV [9], such as the loss of traditional gender roles, poverty, and limited education opportunities. The layering of problems therefore highlights the dynamic interplay between the multi-level structural organisation of refugee settings and the multiple and intersecting social relationships at the community and family levels that correspond to ecological models of human development [13].

Building on the FL findings, KI interviewees' exploration of priority mental health and psychosocial problems bring out their common roots in problems of social cohesion. The relationship between alcohol and drug abuse and mental health problems has been explored in research with Burundian refugees [43], including relating the use of drugs and alcohol to a loss of social control (p.225). Furthermore, Tankink, Ventevogel, et al. [42] highlight the contextually embedded consequences of substance abuse both on individual mental health and wellbeing, and as a factor underpinning disruptions to social cohesion such as gender-based violence. Loss of 
Table 8 The problem of drug abuse/kwishora mu biyobyabwenge (Rwanda)

\section{Description of the problem}

They involve themselves in violence and there are those who stab one another (Bakora urugomo harimo nabateranaga ibyuma)

Coming home drunk, quarrelling (agatongna) and you realized that the family is not tranquil ntumererwe neza)

$\mathrm{He} /$ she changes in his/her talking style, walking style, it means that he/she shows another face (agaragaza indi sura)

There used to be a time they left schools and you realized that they were no longer studying

Falling down while walking and talking obscene (atukana) and also fighting

$\mathrm{He} / \mathrm{she}$ beats another person with no reason

$\mathrm{He} / \mathrm{she}$ can drink and then go to 'gare' (meeting place at the center of the Gihembe camp) and strip naked.

$\mathrm{He} / \mathrm{she}$ throws stones at a car yet he/she is not mad (umusazi) normally

A person may be under influence of drugs and then rape a minor

$\mathrm{He} / \mathrm{she}$ is not afraid, is not obedient (ntiyubaha), and won't be afraid of his/her leaders

It leads some to become bandits (abarara)

When the night falls it is not only the phone he/she can also snatch a handbag from you

\section{Perceived causes of the problem}

Joblessness

Poverty status

The youth that completed school and don't have jobs

Thinking that they are refugees weighs on their minds (No gutekereza ko ari impunzi)

A home that is marred by disputes (amakimbirane)

People lost their parents thus are grieving (bagira intimba) and may have suicidal ideation, and then result into saying 'let's take it' [drugs]

There people are not registered as refugees

There are those UNHCR takes (for resettlement) and others are left behind

\section{Effects on those with the problem and those close to them}

There is no safety (mutekano) [in the camp/quartier] because they cannot sleep since others are fighting

It causes insecurity in the camp. When a person has already taken drugs and there is no one to help him/her, you find that he/she can wound him/herself, commit suicide, there is an incomprehensible robbery and there is also imprisonment

Fighting at home and it can lead to killing one another

They [family members] don't advise one another at home

The poverty status that was in the family keeps increasing

A person who takes them [drugs] if he/she was thinking about marriage, it (marriage) is already out of his/her mind

A person who has a family he can no longer take care of it

The consequences in the quartiers is to fight and cause insecurity

They don't continue with studies nor complete school, they go into the forest

It destroys the whole family (Bisenya umuryango wose)

There is not enough money for children to eat enough so they become malnourished and then suffer from kwashiorkor [severe malnutrition] (Abana barya ntibahage bakagira imirire mibi bakarwara bwaki)

\section{What do people currently do to address the problem}

Counseling is provided (Hajyaho ubujyanama)

Camp management organized meetings and told them about their (drugs) consequences

Teachings from head of quartiers and chiefs of villages

The camp management team come and arrest those who sell them and punish them

It [actions to address the problem] is often done by the government of Rwanda and they also urge us to fight against them

\section{Number of}

respondents

2

1

1

1

1

1

1

1

1

1

Number of respondents

4

2

1

1

1

1

1

1

Number of respondents

4

2 
Table 8 The problem of drug abuse/kwishora mu biyobyabwenge (Rwanda) (Continued)

\begin{tabular}{|c|c|}
\hline [drugs] & \\
\hline Projects that came and helped our boys and girls and take them to study at Gahogo those who had dropped out of schools & 1 \\
\hline $\begin{array}{l}\text { 'Inshuti z' Umwali' (Friends of young lady) they also came and helped girls and boys and gave them what to do instead of } \\
\text { sitting idle }\end{array}$ & 1 \\
\hline $\begin{array}{l}\text { Security organ from the village (umudugudu) to the top is always at hand, when information is shared on time, we quickly } \\
\text { intervene [to address problems] }\end{array}$ & 1 \\
\hline What should be done about the problem if resources were available & $\begin{array}{l}\text { Number of } \\
\text { respondents }\end{array}$ \\
\hline Maybe if possible, all of them should find jobs & 2 \\
\hline If security is back they would go back home (country of origin) & 2 \\
\hline $\begin{array}{l}\text { There is a good thing the government did of taking to a rehabilitation centre, but after } 1 \text { year they should not abandon } \\
\text { them like this, they can find away to bring them together in vocations }\end{array}$ & 2 \\
\hline To sit in the family and talk about it & 3 \\
\hline People who are educated, especially the youth would find what to do (job) & 1 \\
\hline They can be well educated and organize regular counseling sessions (Bakwigishwa cyane, guhozaho ibiganiro bya buri gihe) & 1 \\
\hline $\begin{array}{l}\text { Projects can help the youth and parents and give them support (Imishinga yafasha urubyiruko } n^{\prime} \text { ababyeyi bakabaha na } \\
\text { support [Ubufasha/ inkunga]) }\end{array}$ & 1 \\
\hline People who don't have what to (job) should be given vocations & 1 \\
\hline They can make the procedure of going to America easy & 1 \\
\hline
\end{tabular}

social control is echoed in participants' descriptions of the behaviours of those with alcohol and drug abuse problems that emphasise outward public perception, for example identifying getting lost on the road, being dirty everyday and falling down while walking and talking obscene and also fighting. These descriptions echo another aspect of the COSTAR study which explored what FL participants consider to be a 'good life'. Findings identified the role of outward appearance and dress which are linked with self-esteem and how a person is viewed in the community, including the avoidance of shame (Robinson J, Chiumento A, Kasujja R, Rutayisire R, White R: When you are dirty, you have confidence in you: an exploration of the 'good life', personal appearance, and mental health with Congolese refugees in Rwanda and Uganda, under review).

These connections are echoed in KI findings relating to discrimination/inequity where participants described a lack of love for one another, back-stabbing among different tribes and not respected because you are a refugee. Whilst in Uganda intra-community tensions were structured by gender, tribal, linguistic or religious affiliations; in Rwanda, inter-community inequities were more commonly reported, arising between the treatment of refugees compared to Rwandan nationals. The difference in the internal/external conceptualisation of these problems is potentially related to the structural environment in which refugees are embedded, emphasising the role of the social, economic and political systems for how refugees relate to one another [8], and their host communities. This finding is also echoed in our results on SGBV which highlight the adverse effects of violence on children and young people who experience neglect and mistreatment. These echo studies exploring violence and protection risks for adolescent refugees living in refugee settings in Uganda that highlight the complex interplay of societal norms towards violence [44]; and contextual factors such as divisions within refugee communities as a result of new arrivals which heightened problems of food insecurity, in turn giving rise to psychosocial impacts as a result of hunger [45]. Therefore, our findings suggest complex, inter-linked, and multifaceted relationships between the structural and relational problems experienced by Congolese refugee communities in Rwanda and Uganda that impact on mental health and psychosocial wellbeing.

Specifically, our findings foreground that problems of social cohesion in family and community relations negatively impact the mental health and psychosocial wellbeing of Congolese refugees in Gihembe and Kyangwali. This is evident in participant's descriptions of the effects of problems, for example for the problem of inequity/ discrimination participants' identify this leads to: fighting, hatred within villages, jealousy among people and to lose hope. These effects indicate both low levels of social cohesion seen in a lack of connectedness or sense of belonging, as well as feelings of hopelessness, indicating low levels of mental wellbeing. The interconnected relationship between low levels of social cohesion and poor mental health outcomes has been identified in a recent study with Congolese refugees in Rwanda that highlights the relationship between mental health problems and 
suicidal ideation, and social cohesion including a low sense of connectedness and belonging [46]. Our findings therefore confirm the relevance of conceptual frameworks that emphasise the complex and cyclical relationships between the ecology of refugee settings, encompassing daily stressors, experiences of loss, grief, and continuous social interactions at the community, family and individual levels, and mental health and wellbeing [10-13].

What is absent from the data is the spontaneous identification of problems that directly reference psychological or emotional states commonly recognised in the US and Europe, such as depression or anxiety. Whilst the data does reveal descriptions that may capture culturally bound idioms of distress [47] such as feeling despair, self-isolate and disowning oneself, sadness, lack of self-worth/respect and wanting to forget many bad thoughts, reflecting previous research with conflictaffected populations that identified a common syndrome with core features of sadness and social withdrawal that bore similarities to classifications of mental states such as depression or anxiety [19]. In this study the core conceptualisation of problems with potential mental health and psychosocial impacts were social - including behaviours considered antisocial such as alcohol and drug abuse, violence and gender-based violence; and the systemic problem of discrimination/inequity within and between communities. This problem prioritisation reflects research highlighting the role of social functioning understood as interpersonal interactions in daily life, including access to strong familial and community resources - as an important component of mental health and psychosocial wellbeing [48]. It is also in line with a systematic review that suggests social support seeking from family, friends and community groups is an important component of effective coping strategies in waraffected populations in LMICs [49], with reciprocal networks suggested to be the most beneficial [50]. Our findings reflect multiple qualitative studies with refugees in East Africa and globally that report contextually embedded experiences of interconnected structural and social constellations of refugees' lives that create conditions where social problems, and resulting poor mental health and psychosocial wellbeing, arise $[40,51,52]$.

Consequently, the problems impacting upon mental health and psychosocial wellbeing in this study have their roots in disruptions to social cohesion. As such, proposed interventions should build on interpersonal, familial and community-level supports [9] to support the establishment of social norms that challenge inequity, injustice and abuse [18]. Such an approach offers opportunities to positively re-frame the social conditions that negatively impact mental health and psychosocial wellbeing. This approach resonates with the repeated suggestion of FL and KI participants to provide advice and sensitisation to communities about how to respond to social problems, and to build on community resources to establish educational, vocational and employment opportunities in an effort to reduce negative mental health impacts. This is a central component of the COSTAR project that is working to implement and evaluate a community-based group psychosocial intervention that seeks to promote interactions between individuals and their social environment to reestablish values, norms and relationships; whilst also exploring shared experiences and contextually embedded coping mechanisms that build on the collective strengths and resources of communities to promote mental wellbeing [16]. Alongside such interventions it will also be important for the global community to continue to address structural factors that are recognised to impact upon refugee mental wellbeing, such as refugee integration policies that grant or refuse refugees the right to education and employment opportunities, and the conflict and environmental factors that continue to force people to flee their homes [53].

A unique contribution from this study is the comparison of findings collected with the same methodology in two sites hosting Congolese refugee populations. This is important for understanding the commonalities and differences between the experiences of Congolese refugee communities living in two distinct settings, and for identifying potential opportunities for group-based psychosocial programs to help address the identified problems. Potential study limitations include the number of key informant responses for each problem, notably in Rwanda where adverse weather led to limited access to Gihembe camp to collect data within timelines. However, the high level of congruence of themes, and their confirmation at meetings with community stakeholders including organisations supporting refugees and refugee community representatives, suggest findings are broadly representative of the experiences of Congolese refugees living in Gihembe camp and Kyangwali settlement. Finally, whilst efforts were made to ensure a broad sample including mixed gender, ages, and length of time in the refugee setting to capture the potential diversity of experiences resulting from participant characteristics that affect their daily living, it is possible that the gender affiliations of our research assistants may have affected the engagement of some potential participants.

\section{Reflections on DIME}

The DIME approach applied in this study has two interrelated objectives [1] to elicit an indication of priority problems that Congolese refugees in Gihembe and Kyangwali face to inform the contextual adaptation of a group psychosocial intervention; and [2] to provide local 
language terminology for the translation and adaptation of mental health instruments. We found the first objective to be partially met as study findings provide a understanding of the complex and dynamic interplay of factors impacting upon mental health and psychosocial wellbeing from the perspective of local community participants whose voices may not otherwise be heard. These indicate the sort of problems and proposed solutions participants may bring to a group psychosocial intervention, providing contextual information to situate the intervention in the lives of Congolese refugees. Some of this understanding could also have been obtained through "practice-based evidence" [54] that enters into a dynamic relationship with knowledge, practice and context. This could include for example gaining the knowledgeable insights of local researchers, the practicebased insights of stakeholders such as refugee organisations, and the contextual understanding of refugee community representatives and members. These approaches should continue to prioritise and value diverse community participation and perspectives - including through purposive inclusion of local community members not represented through formal channels - to identify MHPSS priorities and shape interventions, valuing the lived-through experiences of refugees that plays a role beyond research findings $[55,56]$. For the second objective the data obtained has emphasised commonly used linguistic terms in Kiswahili and Kinyarwanda, and encouraged critical reflection on terminology and translation into English [57] in an effort to accurately reflect the precise concerns being voiced. This understanding of language has furthermore been directly incorporated in the translation and contextual adaption of instruments to assess mental health and wellbeing, suggesting this may be where the DIME approach is strongest. Given these reflections further critical reflection on the DIME approach, and potential alternative methods, is recommended.

\section{Conclusion}

Recognising the importance of anchoring MHPSS interventions in the context of refugees' everyday lives, this rapid qualitative study has explored the priority problems of Congolese refugees living in two settings in Uganda and Rwanda. Our study makes an important contribution to the literature on the position of Congolese refugees by exploring the commonalities of experiences across two distinct refugee settings. Notably, findings reveal significant commonalities in the priority problems related to mental health and psychosocial wellbeing that are rooted in problems of social cohesion within refugee communities and between refugee and host communities. This understanding reinforces the importance of proposed intervention approaches that strengthen familial and community-level social relationships to promote positive mental health and psychosocial wellbeing, alongside addressing structural conditions that lead to forced migration and conditions of daily adversity that precipitate mental health problems $[10-13,53]$. Our findings confirm that implementing a community-based group psychosocial support intervention that seeks to foster communities of support by harnessing the collective strengths and resources of refugee communities to promote mental health and psychosocial wellbeing $[16,17]$ offers a potentially appropriate response to addressing the problems identified by participants in this study.

\section{Acknowledgements \\ We would like to acknowledge the COSTAR data collection teams in Uganda and Rwanda: Alice Ishimwe, Hosanne Ingabire, Aimée Mukankusi, Romain Ndikumuzima, Eugenie Muhorakeye, Camille Safari, Eric Niyonteze, Pascal Manirakiza, Olivier Mugwaneza, Barbara Nalwoga Kawooya, Hillary Asiimwe, Bosco Lodu.}

\section{Authors' contributions}

This study was conceptualised by RW, AC, TH, JR, RK, SJ, and PV. The data collection and original-language analysis was conducted by in-country research assistants (see acknowledgements) who were trained and supervised in-country by TH, RK, PB, TR, DK, and SJ; with teleconference support from $A C, J R$ and RW. The first draft of the manuscript was developed by AC, TH, and TR. RK, RN, TR, and DK contributed and verified the interpretation of all original language data. All authors reviewed and edited subsequent manuscript drafts, including contributing relevant literature. All authors have read and approved the final manuscript.

\section{Funding}

The COSTAR study is funded by the Economic \& Social Research Council as part of the Global Challenges Research Fund (ES/S000976/1). The ESRC have no role in the study design, analysis of data, or in the drafting of this article.

\section{Availability of data and materials}

The English data generated and analysed during this study are reported in this published article. The original language datasets generated and analysed for this study are available from the corresponding author on reasonable request.

\section{Ethics approval and consent to participate}

This study was granted ethical approval by ethical review boards at the University of Liverpool, the University of Rwanda, and Makerere University, Uganda National Council for Science and Technology (Makerere reference number: MAKSS REC 11.18.237). All participants provided written informed consent, including to the publication of anonymised results. Additional administrative approvals were obtained to conduct research in Kyangwali refugee settlement (from the Office of the Prime Minister, Uganda), and Gihembe refugee camp (from the Ministry of Emergency Management, Rwanda).

\section{Consent for publication}

Informed consent from participants included consent to the publication of anonymised data.

\section{Competing interests}

All authors declare that they have no competing interests.

\section{Author details}

'Department of Primary Care and Mental Health, University of Liverpool, Liverpool, England. ' ${ }^{2}$ Mental Health and Behaviour Research Group, College of Medicine and Health Sciences, University of Rwanda, Kigali, Rwanda. ${ }^{3}$ CBS Rwanda, Kigali, Rwanda. ${ }^{4}$ Department of Mental Health and Community Psychology, Makerere University, Kampala, Uganda. ${ }^{5}$ Mental Health \& Community Psychology and Behaviour Research Group, College of Medicine and Health Sciences, University of Rwanda, Kigali, Rwanda. ${ }^{6}$ Department of 
Psychiatry, Makerere University, College of Health Sciences, Kampala, Uganda. ${ }^{7}$ Center for Mental Health, College of Medicine and Health Sciences, University of Rwanda, Kigali, Rwanda. ${ }^{8}$ Public Health Section, Division of Resilience and Solutions, United Nations High Commissioner for Refugees, Geneva, Switzerland. ${ }^{9}$ Institute of Health and Wellbeing, University of Glasgow, Glasgow, Scotland.

Received: 9 July 2020 Accepted: 5 November 2020

\section{Published online: 16 November 2020}

\section{References}

1. UNHCR. Figures at a glance 2019 [Available from: https://www.unhcr.org/uk/ figures-at-a-glance.html.

2. Silove $D$, Ventevogel $P$, Rees $S$. The contemporary refugee crisis: an overview of mental health challenges. World Psychiatry. 2017;16(2):130-9.

3. Patel V, Saxena S, Lund C, Thornicroft G, Baingana F, Bolton P, et al. The lancet commission on global mental health and sustainable development. Lancet. 2018:392(10157):1553-98.

4. Charlson F, van Ommeren M, Flaxman A, Cornett J, Whiteford H, Saxena S. New WHO prevalence estimates of mental disorders in conflict settings: a systematic review and meta-analysis. Lancet. 2019;394(10194):240-8.

5. Morina N, Akhtar A, Barth J, Schnyder U. Psychiatric disorders in refugees and internally displaced persons after forced displacement: a systematic review. Front Psychiat. 2018;9:433-57.

6. Harrell-Bond BE. Imposing aid: emergency assistance to refugees. Oxford: Oxford University Press; 1986.

7. Weissbecker I, Hanna F, El Shazly M, Gao J, Ventevogel P. Integrative mental health and psychosocial support interventions for refugees in humanitarian crisis settings. In: Wenzel T, Drozdek B, editors. Uncertain safety: understanding and assisting the 21 st century refugees. Cham: Springer; 2019. p. 117-53.

8. Buckley-Zistel S, Krause U. Gender, violence, refugees: an introduction. In: Buckley-Zistel S, Krause U, editors. Gender, Violence, Refugees. Oxford: Berghahn Books; 2017. p. 1-18.

9. Tankink M. 'We are now married with the UNHCR': domestic violence in the context of refugee camps. In: Tankink M, Vysma M, editors. Roads and boundaries: travels in search of (re)connection. Netherlands: AMB; 2011. p. 216-25.

10. Miller KE, Rasmussen A. War exposure, daily stressors, and mental health in conflict and post-conflict settings: bridging the divide between traumafocused and psychosocial frameworks. Soc Sci Med. 2010;70(1):7-16.

11. Miller KE, Rasmussen A. The mental health of civilians displaced by armed conflict: an ecological model of refugee distress. Epidemiol Psychiatr Sci. 2017;26(2):129-38

12. Hobfoll SE. Conservation of resources: a new attempt at conceptualizing stress. Am Psychol. 1989;44(3):513-24.

13. Bronfenbrenner U. Making human beings human: bioecological perspectives on human development. California: SAGE Publications; 2004.

14. Otake Y. Community resilience and long-term impacts of mental health and psychosocial support in northern Rwanda. Int J Med Sci. 2018;6(4):94-113.

15. UNHCR. A community-based approach in UNHCR operations. Geneva: UNHCR; 2008.

16. Jansen S, White R, Hogwood J, Jansen A, Gishoma D, Mukamana D, et al. The "treatment gap" in global mental health reconsidered: sociotherapy for collective trauma in Rwanda. Eur J Psychotraumatol. 2015;6(0):1-6.

17. Hobfoll SE. Conservation of resources and disaster in cultural context: the caravans and passageways for resources. Psychiatry. 2012;75(3):227-32.

18. Ministry of Foreign Affairs. Mind the Mind Now: International Conference on Mental Health \& Psychosocial Support in Crisis Situations 2019. The Netherlands: Ministry of Foreign Affairs, Government of the Netherlands; 2019.

19. Ventevogel $P$, Jordans $M$, Reis $R$, de Jong J. Madness or sadness? Local concepts of mental illness in four conflict-affected African communities. Confl Heal. 2013;7(1):3-18.

20. Bolton P, Tang AM. Using ethnographic methods in the selection of postdisaster, mental health interventions. Prehosp Disaster Med. 2004;19(1):97-101.

21. Applied Mental Health Research Group. Design, implementation, monitoring and evaluation of mental health and psychosocial assistance programs for trauma survivors in low resource countries: a user's manual for researchers and progam implementers (adult version). Module 1: Qualitative Assessment. Baltimore: Johns Hopkins University Bloomberg School of Public Health; 2013.
22. ISRCTN Registry (2019) 'Community-based Socio-therapty Adapted for Refugees: the COSTAR study [ISRCTN20474555]', ISRCTN Registery. Available at: http://www.isrctn.com/ISRCTN20474555.

23. Bolton P, Michalopoulos L, Ahmed AM, Murray LK, Bass J. The mental health and psychosocial problems of survivors of torture and genocide in Kurdistan, northern Iraq: a brief qualitative study. Torture. 2013;23(1):1-14.

24. Bolton P, Surkan PJ, Gray AE, Desmousseaux M. The mental health and psychosocial effects of organized violence: a qualitative study in northern Haiti. Transcult Psychiatry. 2012;49(4):590-612.

25. Poudyal B, Bass J, Subyantoro T, Jonathan A, Erni T, Bolton P. Assessment of the psychosocial and mental health needs, dysfunction and coping mechanisms of violence affected populations in Bireuen Aceh. A qualitative study. Torture. 2009;19(3):218-26.

26. Coghlan B, Brennan RJ, Ngoy P, Dofara D, Otto B, Clements M, et al. Mortality in the Democratic Republic of Congo: a nationwide survey. Lancet. 2006;367(9504):44-51.

27. Johnson K, Scott J, Rughita B, Kisielewski M, Asher J, Ong R, et al. Association of sexual violence and human rights violations with physical and mental health in territories of the eastern Democratic Republic of the Congo. J Am Med Assoc. 2010;304(5):553-62.

28. UNHCR. DRC Regional Refugee Response Plan: January 2020-December 2021. Office of the Bureau for Southern Africa in Pretoria. South Africa: UNHCR; 2019.

29. UNHCR. Population profile of refugee camps in Rwanda - as of 31st March 2015. Kigali: UNHCR; 2015. Available from: https://data2.unhcr.org/en/ documents/download/48347.

30. UNHCR. UNHCR's presence in Rwanda 2016 [Available from: https://www. unhcr.org/rw/66-overview-2.html.

31. UNHCR. Refugees and Asylum seekers in Uganda. Uganda Refugee Response 2019 [Available from: https://ugandarefugees.org/en/country/uga.

32. UNHCR. Uganda - Refugee Statistics May 2020 - Kyangwali. 2020.

33. United Nations. New York declaration for refugees and migrants (a/RES/71/ 1). New York: United Nations; 2016.

34. Betts A, Chaara I, Omata N, Sterck O. Refugee economies in Uganda : what difference does the self-reliance model make? Oxford: Refugee Studies Centre; 2019.

35. Office of the Prime Minister. Comprehensive Refugee Response Framework Uganda 2017 [Available from: https://opm.go.ug/comprehensive-refugeeresponse-framework-uganda/.

36. Office of the Prime Minister, UNHCR. Uganda - Refugee Statistics July 2019 Kyangwali. 2019

37. Santaella-Tenorio J, Bonilla-Escobar FJ, Nieto-Gil L, Fandiño-Losada A, Gutiérrez-Martínez MI, Bass J, et al. Mental health and psychosocial problems and needs of violence survivors in the Colombian Pacific coast: a qualitative study in Buenaventura and Quibdó. Prehosp Disaster Med. 2018; 33(6):567-74.

38. Forrest R, Kearns A. Social cohesion, social capital and the Neighbourhood. Urban Stud. 2001;38(12):2125-43.

39. Manca AR. Social cohesion. In: Michalos AC, editor. Encyclopedia of quality of life and well-being research. Dordrecht: Springer Netherlands; 2014. p. $6026-8$.

40. Sen A. Development as capability expansion. In: Fukuda-Parr S, Kumar AS, editors. Readings in human development: concepts, measures and policies for a development paradigm. Oxford: Oxford University Press; 2003.

41. Adaku A, Okello J, Lowry B, Kane JC, Alderman S, Musisi S, et al. Mental health and psychosocial support for south Sudanese refugees in northern Uganda: a needs and resource assessment. Confl Heal. 2016;10(1):18-27.

42. Tankink M, Ventevogel $P$, Ntiranyibagira L, Ndayisaba A, Ndayisaba $H$. Situation and needs assessment of mental health and psychosocial support in refugee camps in Tanzinia, Rwanda and Burundi. Unpublished report: HealthNet TPO; 2010.

43. Ventevogel P. The effects of war: local views and priorities concerning psychosocial and mental health problems as a result of collective violence in Burundi. Intervention. 2015;13(3):216-34.

44. Bermudez LG, Parks L, Meyer SR, Muhorakeye L, Stark L. Safety, trust, and disclosure: a qualitative examination of violence against refugee adolescents in Kiziba Camp, Rwanda. Soc Sci Med. 2018;200:83-91.

45. Meyer SR, Meyer E, Bangirana C, Mangen PO, Stark L. Protection and wellbeing of adolescent refugees in the context of a humanitarian crisis: perceptions from South Sudanese refugees in Uganda. Soc Sci Med. 2019; 221:79-86. 
46. Ingabire CM, Richters A. Suicidal Ideation and Behavior Among Congolese Refugees in Rwanda: Contributing Factors, Consequences, and Support Mechanisms in the Context of Culture. Front Psychiatry. 2020;11(299). https://doi.org/10.3389/fpsyt.2020.00299.

47. Nichter M. Idioms of distress revisited. Cult Med Psychiatry. 2010;34(2):401-16.

48. Lahiri S, van Ommeren M, Roberts B. The influence of humanitarian crises on social functioning among civilians in low- and middle-income countries: a systematic review. Global Public Health. 2017;12(12):1461-78.

49. Seguin M, Roberts B. Coping strategies among conflict-affected adults in low- and middle-income countries: a systematic literature review. Global Public Health. 2017;12(7):811-29.

50. Pedersen D, Tremblay J, Errazuriz C, Gamarra J. The sequelae of political violence: assessing trauma, suffering and dislocation in the Peruvian highlands. Soc Sci Med. 2008;67(2):205-17.

51. Bragin M, Onta K, Janepher T, Nzeyimana G, Eibs T. To be well at heart: women's perceptions of psychosocial wellbeing in three conflict affected countries. Intervention. 2014;12(2):187-209.

52. Horn R. 'An evaluatio of the Kakuma Emotional Wellbeing Interview (KEWI)'. Intervention. 2008;7(3):223-38.

53. Gurtov M. Open borders: a global-humanist approach to the refugee crisis. World Dev. 1991;19(5):485-96.

54. Kienzler H. Mental health system reform in contexts of humanitarian emergencies: toward a theory of "practice-based evidence". Cult Med Psychiatry. 2019:43(4):636-62.

55. Sen A. Capabilities, lists, and public reason: continuing the conversation. Fem Econ. 2004:10(3):77-80.

56. Nuffield Council on Bioethics. Research in Global Health Emergencies: Ethical Issues. London: Nuffield Council on Bioethics; 2020.

57. Jane A, Richard F, Ross W. What Shapes Everyday Translanguaging? Insights from a Global Mental Health Project in Northern Uganda. In:

Translanguaging as everyday practice, vol. 28. Cham: Springer International PublishingMultilingual Education; 2018. p. 257-73.

\section{Publisher's Note}

Springer Nature remains neutral with regard to jurisdictional claims in published maps and institutional affiliations.

Ready to submit your research? Choose BMC and benefit from:

- fast, convenient online submission

- thorough peer review by experienced researchers in your field

- rapid publication on acceptance

- support for research data, including large and complex data types

- gold Open Access which fosters wider collaboration and increased citations

- maximum visibility for your research: over $100 \mathrm{M}$ website views per year

At $\mathrm{BMC}$, research is always in progress.

Learn more biomedcentral.com/submissions 